\title{
OPEN Non-fusion palliative spine surgery without reconstruction is safe and effective in spinal metastasis patients: retrospective study
}

\author{
Siravich Suvithayasiri ${ }^{1}$, Borriwat Santipas ${ }^{2}$, Sirichai Wilartratsami ${ }^{2}$,
} Monchai Ruangchainikom² \& Panya Luksanapruksa ${ }^{2 \bowtie}$

Considering the shorter life expectancy and poorer prognosis of metastatic epidural spinal cord compression patients, anterior reconstruction and fusion may be unnecessary. This study aimed to investigate the outcomes of palliative surgery for metastatic epidural spinal cord compression with neurological deficit among patients who underwent posterior decompression and instrumentation without fusion or anterior reconstruction. This single-center retrospective review included all patients aged $>\mathbf{1 8}$ years with thoracic or lumbar spinal metastasis who were surgically treated for metastatic spinal cord compression without fusion or anterior reconstruction at the Department of Orthopaedic Surgery, Faculty of Medicine Siriraj Hospital, Mahidol University, Bangkok, Thailand during July 2015 to December 2017. Data from preoperation to the 1-year follow-up, including demographic and clinical data, Frankel classification, pain scores, complication, revision surgery, health-related qualityof-life scores, and survival data, were collected and analyzed. A total of 30 patients were included. The mean age was $59.83 \pm 11.73$ years, and $20(66.7 \%)$ patients were female. The mean operative time was $208.17 \pm 58.41 \mathrm{~min}$. At least one Frankel grade improvement was reported in $53.33 \%$ of patients. The pain visual analog scale, the EuroQOL five-dimension five-level utility score, and the Oswestry Disability Index were all significantly improved at a minimum of 3 months after surgery. No intraoperative mortality or instrument-related complication was reported. The mean survival duration was $11.4 \pm 8.97$ months. Palliative non-fusion surgery without anterior reconstruction may be considered as a preferable choice for treating spinal metastasis patients with spinal cord compression with neurological deficits.

Spinal metastasis is a known cause of severe pain and neurological deficit, and these effects adversely affect patient quality of life. Combination treatment of surgery and radiation was superior to radiation alone in patients with spinal metastasis relative to ambulation status and the need for analgesia ${ }^{1}$. Decompression via a posterior approach with or without instrumentation was reported to be a preferable surgical strategy ${ }^{2}$. Furthermore, many studies found good to excellent outcomes with the addition of anterior column reconstruction and fusion ${ }^{3-9}$. However, this patient population has a shorter life expectancy and a poorer prognosis, so it has been argued that these add-on procedures may unnecessarily increase operative time, intraoperative blood loss, and postoperative morbidity ${ }^{10,11}$.

This study aimed to investigate the outcomes of palliative surgery for metastatic epidural spinal cord compression with neurological deficit among patients who underwent posterior decompression and instrumentation without fusion or anterior reconstruction. We hypothesized that postoperative health-related quality-of-life (HRQoL) scores would be significantly improved.

\section{Material and methods}

This single-center retrospective review included all patients aged $>18$ years with thoracic (T1-T10), thoracolumbar (T11-L1), or lumbar (L2-L5) spinal metastasis who underwent posterior decompression and instrumentation without fusion or anterior reconstruction for symptomatic metastatic spinal cord compression with the

${ }^{1}$ Orthopedic Center, Chulabhorn Hospital, HRH Princess Chulabhorn College of Medical Science, Chulabhorn Royal Academy, Bangkok, Thailand. '2Department of Orthopedic Surgery, Faculty of Medicine, Siriraj Hospital, Mahidol University, 2 Wanglang Road, Bangkoknoi, Bangkok 10700, Thailand. ${ }^{\varpi}$ email: cutecarg@yahoo.com 
neurological deficit at the Department of Orthopaedic Surgery, Faculty of Medicine Siriraj Hospital, Mahidol University, Bangkok, Thailand during July 2015 to December 2017. Patients with unknown primary cancer origin, who underwent fusion, and/or who received anterior reconstruction were excluded. Patient demographic and clinical data, including age, gender, primary cancer origin, and spinal region involvement, were collected. The patient's neurological status was assessed using the Frankel grading system. The health-related quality-of-life (HRQoL) was evaluated using the pain visual analog scale (VAS), the Oswestry Disability Index (ODI), and the EuroQOL five-dimension five-level (EQ5D5L) utility score. These assessment parameters were collected and compared between the pre-operative period and the 3-month, 6-month, and 12-month postoperative followups. Surgery-related complication data, operative time, estimated blood loss, and length of hospital stay was also recorded and analyzed. Overall survival was calculated from the date of surgery to the date of final follow-up or death.

The Institutional Review Board (IRB) of the Faculty of Medicine Siriraj Hospital approved this study and approved for an exemption of informed consent, certificate of approval 833/2557(EC2). All the patient profiled was concealed by using the case number instead. All methods were performed following the relevant guidelines and regulations.

Surgical technique. All patients were positioned in the prone position on either a Jackson spine table or a radiolucent table with two horizontally placed padded bolsters. A midline incision was then made at the affected region of the spine. Whether a conventional open or percutaneous technique was used, instrumentation with pedicle screws was performed at least two levels above and two below the involved vertebrae. Posterior decompression was then performed via total laminectomy at the involved level and at least one level above and below the involved level. In some cases, partial facetectomy and pedicle resection were also performed to facilitate further resection of the tumor. Example cases that underwent surgery were shown in Fig. 1 and Fig. 2. After surgery, all patients received local radiotherapy and targeted and/or systemic chemotherapy according to our center's multidisciplinary team approach guideline.

Statistical analysis. Descriptive data in this study is presented as a number, and percentage, mean plus/ minus standard deviation, or median and interquartile range. To compensate for multiple comparisons performed at three different points of time, Bonferroni correction was employed. That analysis yielded a statistical significance threshold of $p<0.017$. Student's $t$-test was used to compare all of the HRQoL assessments between time points. Overall survival was assessed using Kaplan-Meier survival analysis. All statistical analyses were performed using SPSS Statistics version 21.0 (IBM Corporation; SPSS, Inc., Chicago, IL, USA).

\section{Results}

A total of 30 patients ( 10 males, 20 females) with a mean age of $59.83 \pm 11.73$ years were enrolled. The lumbar (33.3\%) and thoracic (30\%) regions were the first and second most involved regions (Table 1). The breast was the most common primary tumor site $(40 \%)$, followed by lung $(26.7 \%)$ and prostate $(13.3 \%)$. Other primary cancer sites included the cervix, colon, liver, renal, and tonsil (3.3\% each) (Table 1).

Regarding pre-operative neurological status, Frankel grade $\mathrm{C}$ was found in $53.33 \%$ of the patients, followed by $36.67 \%$ for grade D and $10 \%$ for grade B. No patients were preoperatively rated grade A or grade E. Just over one-half of patients (53.33\%) experienced an improvement of at least one Frankel grade during the early postoperative period (Table 2).

The pre-operative pain VAS was $57.83 \pm 22.84$, and that value was improved after surgery to $26.25 \pm 21.67$ at 3 months $(p<0.001)$, to $25.5 \pm 26.29$ at 6 months, and $11.67 \pm 9.83$ at 12 months. The mean pre-operative ODI was $65.35 \pm 17.09$, and that parameter was significantly improved postoperatively to $48.33 \pm 19.69$ at 3 months $(p<0.001)$, to $37.27 \pm 24.46$ at 6 months $(p=0.006)$, and $28.59 \pm 15.0$ at 12 months $(p=0.002)$. The mean preoperative EQ5D5L utility score was $0.40 \pm 0.33$, with postoperative improvement to $0.66 \pm 0.32$ at 3 months $(p<0.001)$, to $0.75 \pm 0.36$ at 6 months, and $0.92 \pm 0.07$ at 12 months $(p=0.014)$ (Table 3$)$.

The average estimated blood loss was $750.67 \pm 529.20 \mathrm{ml}$ (median: 600, IQR: 813 ), the average operative time was $208.17 \pm 58.41 \mathrm{~min}$ (median: 190 ; IQR: 80 ), and the average length of hospital stay was $14.4 \pm 9.47$ days (median: 11.5; IQR: 6.25).

A total of four postoperative complications were reported. Three patients had wound dehiscence and infection, and another patient had a local recurrence with progressive neurological deficit (Table 4). Wound complication onset in those 3 patients occurred during 2 weeks to 2 months postoperatively, and all 3 underwent aggressive wound debridement, resuturing, and antibiotic therapy. The patient with local recurrence underwent an extended decompression revision surgery at 4 months postoperatively, and no intra-operative complication was reported.

Kaplan-Meier analysis estimated the mean survival duration to be $346.83 \pm 273.04$ days or 11.4 months (median: 338 days, IQR: 516.50-107.75) (Fig. 3).

\section{Discussion}

Spinal metastasis occurs in about $20 \%$ of all patients with cancer ${ }^{12,13}$, and about $5-10 \%$ develop spinal cord compression $^{14,15}$. Generally, the treatment for spinal metastasis is palliative, aiming to achieve pain relief, maintenance or recovery of neurological function, local durable tumor control, spinal stability, and improved quality of life. The current treatment strategies of spinal metastases included stereotactic spinal radiosurgery (SRS) ${ }^{16}$, chemotherapy, and/or surgery. The purposes are pain relief and control of paralysis-maintaining their performance status ${ }^{17}$. However, in patients with epidural spinal cord compression and/or spinal instability, palliative surgery may be considered as optimal treatment. Lee et al. ${ }^{18}$ aimed to predict the vertebral compression fractures 

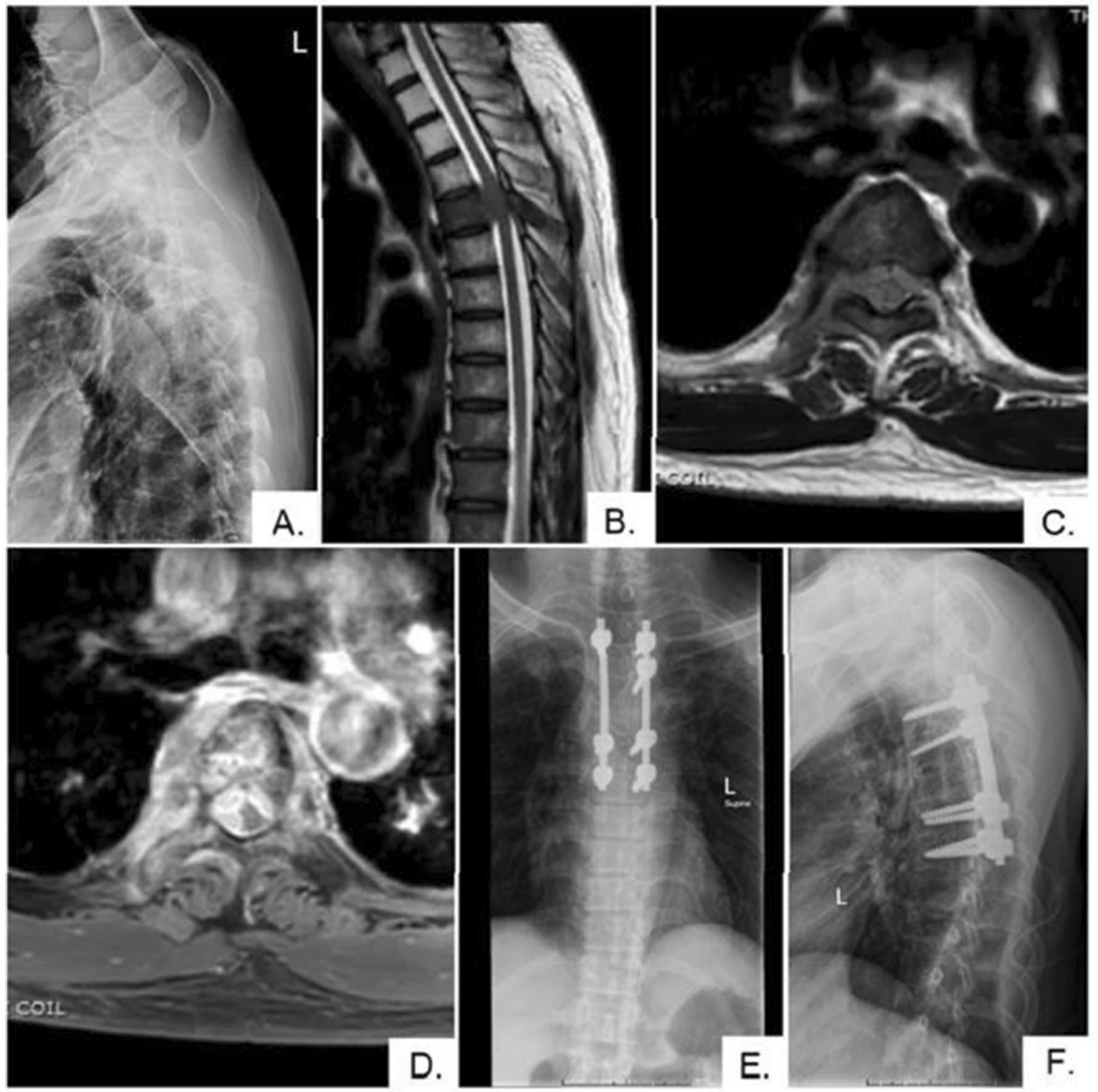

Figure 1. A 57-year-old male patient with tonsil cancer (case No. 14). (A, B) Lateral plain radiograph and sagittal T2-weighted magnetic resonance image (MRI) showing the mild collapse of the T5 vertebra and bone marrow involvement in the vertebral body due to metastases-extending posteriorly into the spinal canal compressing the spinal cord. (C, D) Axial T2-weighted and T1-weighted contrast-enhanced MRI confirm the tumor extension into the spinal canal. (E, F) Anteroposterior and lateral plain radiograph obtained 3 months after posterior instrumentation and decompression without anterior reconstruction, showing no implant-related complication. Please note that the tumor was already involved at the right T4 pedicle at the time of surgery. Thus, the surgeon was unable to insert the pedicular screw securely.

(VCFS) after the use of the spinal instability neoplastic score (SINS) prior to SRS in a metastatic spine. They found that patients with higher SINS were more likely to experience symptomatic fractures (31.6\%) than those with lower SINS (7.4\%). Furthermore, high SINS was a significant risk factor for VCFs after this non-surgical treatment on univariate and multivariate analysis. Therefore, this could also raise the importance of surgical treatment as a valid option in our patients' who mostly present with high SINS, which means spinal instability.

Palliative surgery is one of the treatment modalities of choice in selected patients, intending to achieve adequate spinal cord decompression and stabilization of the metastatic spine ${ }^{19}$. The posterior approach is still the most popular option in the thoracic and lumbar spinal regions due to its simplicity and surgeon familiarity ${ }^{2}$. Several authors have suggested adding anterior reconstruction and/or fusion procedures to achieve even more circumferential decompression and stability. In 2004, Lewandrowski et al. ${ }^{5}$ reported a case series of 30 patients with primary spinal bone tumor or metastasis treated by anterior vertebral reconstruction with fresh-frozen cortical bone allograft with anterior and posterior instrumentation. Despite the high rate of intraoperative or postoperative complications (up to $46 \%$ ), the authors proposed the anterior column reconstruction technique as being a reliable technique for treating patients with spinal tumors. Jandial et al. ${ }^{8}$ conducted a retrospective case review of 11 patients with spinal metastasis who underwent single-stage posterior-only vertebral column 

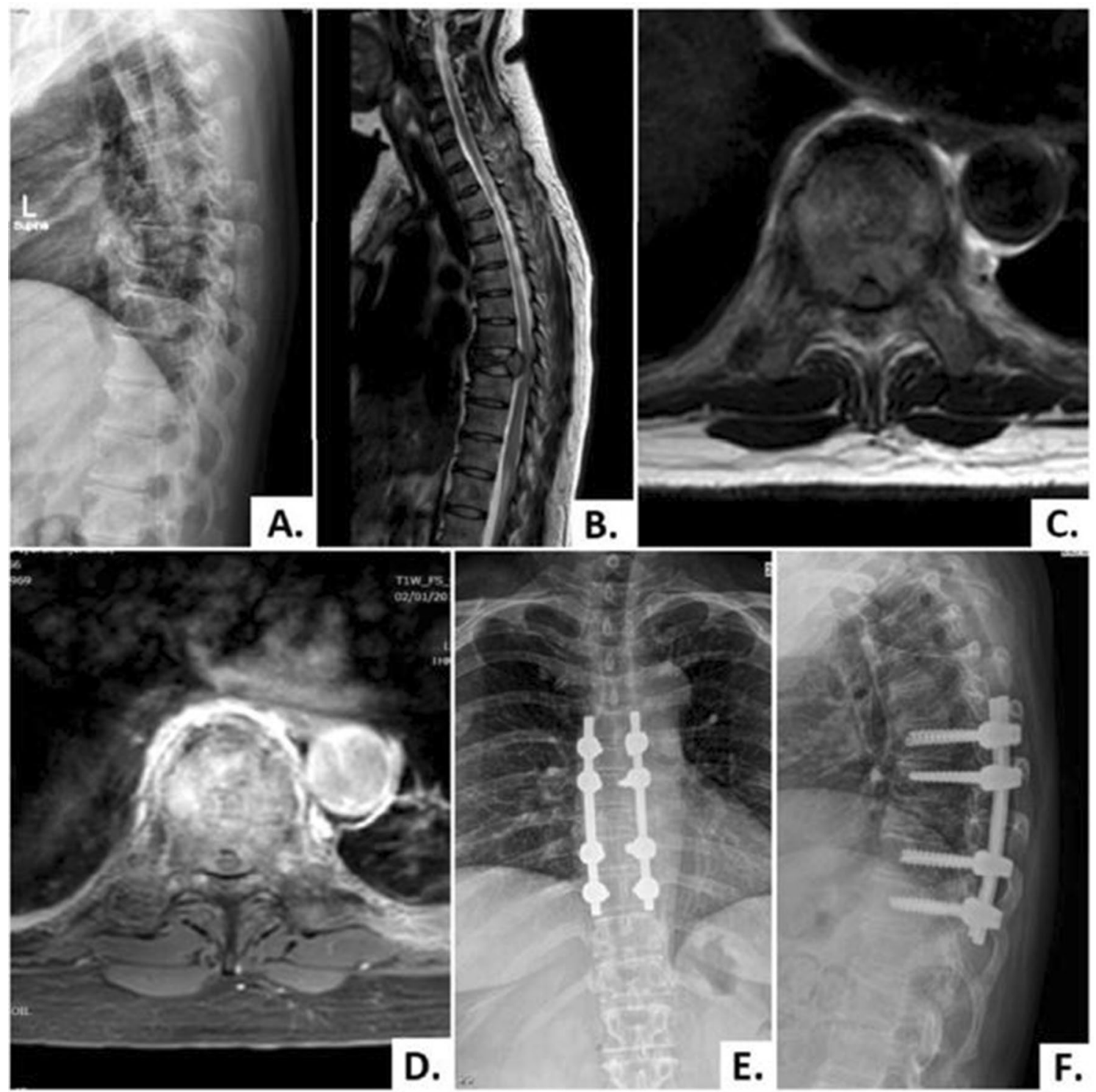

Figure 2. A 49-year-old female patient with breast cancer (case No. 15). (A, B) Lateral plain radiograph and sagittal T2-weighted MRI showed the collapse of the T8 vertebra and metastases tumor infiltration at the vertebral body with extension posteriorly into the spinal canal. (C, D) Axial T2-weighted and T1-weighted contrast-enhanced MRI showing enhancement of the vertebral body and both sides of pedicles with the metastatic tumor extension already encased and compressing the spinal cord. (E, F) Postoperative anteroposterior and lateral plain radiograph obtained at 3-month follow-up visit showing proper implant position without loss of fixation.

resection and reconstruction with an expandable cage and pedicle screw fixation. They concluded that their approach was viable, and the use of an expandable cage might reduce morbidity associated with extensive mobilization of the nerve roots. Recently, Gezercan et al. ${ }^{9}$ reported a case series of 22 patients who underwent a single-stage posterolateral transpedicular approach with 360-degree stabilization and vertebrectomy in patients with primary or metastatic tumors of the spine. They found the pain VAS and Frankel scores significantly improved postoperatively, and they concluded that their technique is less risky, relatively safe, and less invasive.

Although some studies reported good to excellent results, as mentioned above, others found the add-on procedure(s) to be associated with a higher complication rate, prolonged operative time, and more blood loss. Cahill et al. ${ }^{10}$ conducted a review of 43 cases in 1999. Even though all of their patients remained pain-free until days before they died, they found the use of near-total vertebrectomy followed by anterior and posterior reconstruction to be limited in those with a limited life expectancy. Chen et al. ${ }^{11}$ retrospectively reviewed the surgical results of 23 patients with symptomatic metastatic spinal cord compression at the thoracic spine. They reported comparable outcomes after palliative surgery without anterior vertebral reconstruction, and they concluded that reconstruction might be unnecessary. A recent systematic review by Altaf et al. ${ }^{20}$ found that even though some studies support anterior reconstruction, all of those studies had low to very low evidence quality. Taken together, the aforementioned evidence seems to suggest that the shorter life expectancy and poorer prognosis in 


\begin{tabular}{|c|c|c|c|c|c|c|}
\hline \multirow[b]{2}{*}{ Case no } & \multirow[b]{2}{*}{ Gender, age ranges (years) } & \multirow[b]{2}{*}{ Primary tumor } & \multirow[b]{2}{*}{ Location } & \multicolumn{2}{|l|}{ Frankel grade } & \multirow[b]{2}{*}{ Survival (days) } \\
\hline & & & & Pre-operative & Postoperative & \\
\hline 1 & F, 60-69 & Breast & T3 & B & $\mathrm{D}$ & 1000 \\
\hline 2 & F, 70-79 & Lung & L5 & $\mathrm{D}$ & $\mathrm{D}$ & 129 \\
\hline 3 & F, 60-69 & Lung & T5, T6, T11 & C & $\mathrm{D}$ & 325 \\
\hline 4 & F, 80-89 & Bladder & L5 & C & $\mathrm{C}$ & 134 \\
\hline 5 & F, 40-49 & Breast & L1-5 & C & C & 27 \\
\hline 6 & F, 50-59 & Breast & L4 & $\mathrm{D}$ & $\mathrm{D}$ & 65 \\
\hline 7 & F, 50-59 & Breast & L4 & C & $\mathrm{D}$ & 332 \\
\hline 8 & F, 50-59 & Breast & T12, L1, L3-4 & $\mathrm{D}$ & $\mathrm{D}$ & 768 \\
\hline 9 & F, 40-49 & Breast & T3-6, L3 & C & E & $971^{*}$ \\
\hline 10 & M, 50-59 & Liver & T4 & B & B & 198 \\
\hline 11 & F, 60-69 & Lung & T3 & C & $\mathrm{D}$ & $134^{*}$ \\
\hline 12 & M, 50-59 & Lung & L3 & C & $\mathrm{D}$ & 572 \\
\hline 13 & F, 70-79 & Lung & T6-9 & C & $\mathrm{D}$ & $647^{*}$ \\
\hline 14 & M, 50-59 & Tonsil & T5 & C & C & 635 \\
\hline 15 & F, 40-49 & Breast & T8 & C & $\mathrm{D}$ & $49^{*}$ \\
\hline 16 & F, 50-59 & Breast & T11, L4, L5 & C & $\mathrm{D}$ & 77 \\
\hline 17 & F, 30-39 & Breast & L4-5 & $\mathrm{D}$ & $\mathrm{D}$ & 280 \\
\hline 18 & F, 60-69 & Breast & T11, L1, L5 & C & $\mathrm{D}$ & 346 \\
\hline 19 & F, 60-69 & Breast & T12 & $\mathrm{D}$ & E & $379^{*}$ \\
\hline 20 & F, 70-79 & Breast & L5 & $\mathrm{D}$ & $\mathrm{D}$ & $383^{*}$ \\
\hline 21 & F, 50-59 & Cervix & L4 & $\mathrm{D}$ & $\mathrm{D}$ & $442^{*}$ \\
\hline 22 & M, 50-59 & Colon & L2 & $\mathrm{D}$ & $\mathrm{D}$ & 417 \\
\hline 23 & M, 40-49 & Lung & T1-2 & B & B & 40 \\
\hline 24 & M, 60-69 & Lung & T10 & $\mathrm{D}$ & E & $498^{*}$ \\
\hline 25 & F, 60-69 & Lung & L4-5 & C & $\mathrm{D}$ & $631^{*}$ \\
\hline 26 & M, 60-69 & Prostate & L4-5 & $\mathrm{D}$ & E & 77 \\
\hline 27 & M, 70-79 & Prostate & T3, T4, T7-8 & C & C & 118 \\
\hline 28 & M, 70-79 & Prostate & L2 & $\mathrm{D}$ & E & $344^{*}$ \\
\hline 29 & M, 60-69 & Prostate & T3 & C & D & $351^{*}$ \\
\hline 30 & F, 60-69 & Renal & L2, L4 & C & C & 36 \\
\hline
\end{tabular}

Table 1. Demographic and clinical data of 30 metastatic epidural spinal cord compression patients who underwent posterior decompression and stabilization with neither fusion nor anterior reconstruction. ${ }^{\star}$ Patient was still alive at the time of the most recent contact.

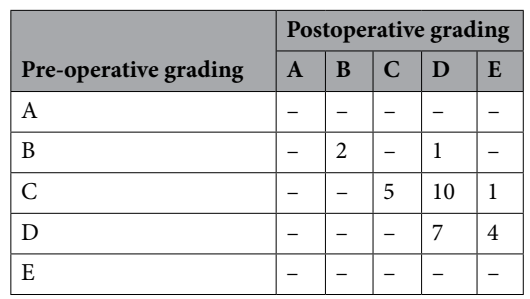

Table 2. Frankel's grade was compared between the pre-operative and postoperative periods.

this patient population warrant the use of less invasive procedures (such as posterior decompression and instrumentation alone, as described in this study) that yield favorable outcomes and that improve patient quality-of-life.

In general, neurological functions and ambulatory status are significant factors that affect overall patient quality-of-life in metastatic epidural spinal cord compression (MESCC) patients ${ }^{21}$. In our study, 16 of 30 patients (53.3\%) had at least one level of Frankel grade improvement within the early postoperative period. However, most patients returned to Frankel $D$ grade, which is characterized by some motor power loss, but they were still able to ambulate with or without gait aid. Several studies (with or without anterior reconstruction and/or fusion) reported similar results. A recent study by Itshayek et al. ${ }^{22}$ reported that 20 of 34 elderly MESCC patients $(58.8 \%)$ had at least one-grade improvement in their American Spinal Injury Classification (ASIA) impairment scale score after surgery. Similarly, Ju DG et al. ${ }^{21}$ reported that 5 of 9 pre-operative non-ambulatory patients $(56 \%)$ 


\begin{tabular}{|c|c|c|}
\hline HRQoL score & Mean \pm SD & $P$ value \\
\hline \multicolumn{3}{|l|}{ Pain VAS (0-100) } \\
\hline Preoperative $(\mathrm{n}=30)$ & $57.83 \pm 22.84$ & \\
\hline 3 months $(\mathrm{n}=28)$ & $26.25 \pm 21.67$ & $<0.001^{\star}$ \\
\hline 6 months $(\mathrm{n}=10)$ & $25.5 \pm 26.29$ & 0.019 \\
\hline 1 year $(n=6)$ & $11.67 \pm 9.83$ & 0.03 \\
\hline \multicolumn{3}{|l|}{ ODI (0-100) } \\
\hline Preoperative $(\mathrm{n}=30)$ & $65.35 \pm 17.09$ & \\
\hline 3 months $(\mathrm{n}=28)$ & $48.33 \pm 19.69$ & $<0.001 *$ \\
\hline 6 months $(\mathrm{n}=10)$ & $37.27 \pm 24.46$ & $0.006^{*}$ \\
\hline 1 year $(n=6)$ & $28.59 \pm 15.08$ & $0.002^{*}$ \\
\hline \multicolumn{3}{|c|}{ EQ5D5L utility score (-1 to 1) } \\
\hline Preoperative $(\mathrm{n}=30)$ & $0.40 \pm 0.33$ & \\
\hline 3 months $(\mathrm{n}=28)$ & $0.66 \pm 0.32$ & $<0.0011^{*}$ \\
\hline 6 months $(\mathrm{n}=10)$ & $0.75 \pm 0.36$ & 0.116 \\
\hline 1 year $(n=6)$ & $0.92 \pm 0.07$ & $0.014^{\star}$ \\
\hline
\end{tabular}

Table 3. Patient health-related quality-of-life (HRQoL) scores compared between preoperation and each follow-up visit until 1 year after surgery. ${ }^{\star}$ Indicates a statistically significant difference $(p<0.017)$ (alpha level was adjusted using Bonferroni method). VAS, visual analog scale; ODI, Oswestry Disability Index; EQ5D5L utility score, EuroQOL five-dimension five-level utility score.

\begin{tabular}{|l|l|}
\hline Complication & $\mathbf{n}$ \\
\hline Neurological progression & $1^{\star}$ \\
\hline Wound infection/dehiscence & 3 \\
\hline Cerebral spinal fluid leakage & 0 \\
\hline Instrumentation failure & 0 \\
\hline Local recurrence & $1^{\star}$ \\
\hline Revision surgery & $1^{\star}$ \\
\hline Intraoperative mortality & 0 \\
\hline
\end{tabular}

Table 4. Postoperative complications. ${ }^{*}$ These complications occurred in the same case.

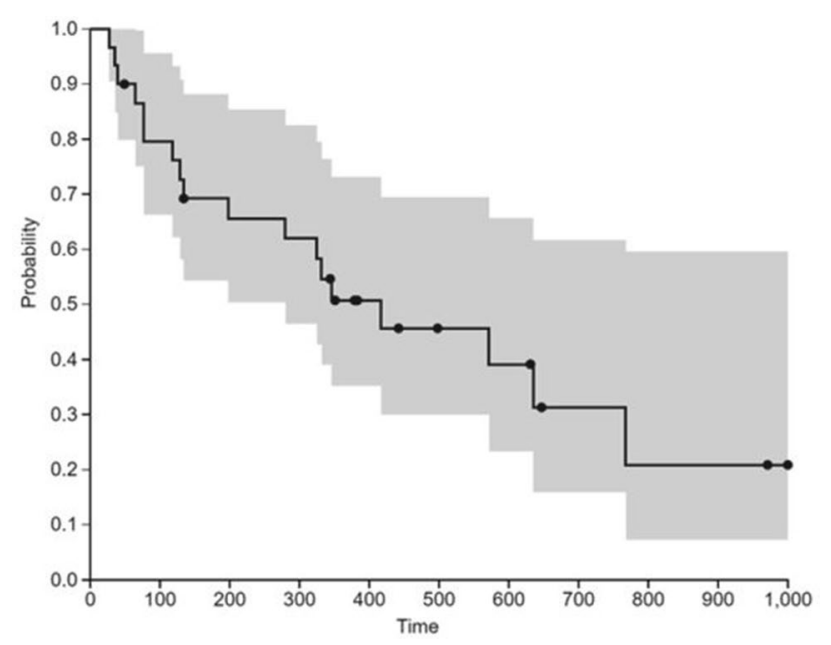

Figure 3. Kaplan-Meier survival curve of the 30 MESCC patients who underwent posterior decompression and stabilization without neither fusion nor anterior reconstruction surgery (black circle $=$ censored observations). 
regained ambulation within one year after surgery. Furthermore, Chang et al. ${ }^{24}$ described improvement of at least one Frankel grade in 22 of 29 MESCC patients (75.9\%) who underwent palliative surgery without anterior vertebral reconstruction in the lower thoracic or thoracolumbar region.

In our study, the evaluated surgical strategy was found to be relatively safe. The average estimated blood loss and operative time were $750 \mathrm{ml}$ and $208.17 \mathrm{~min}$, respectively. Even though $13 \%$ of our patients had surgeryrelated complications (three wound complications and one local recurrence with progressive neurological deficit who eventually underwent revision surgery), no cerebrospinal fluid (CSF) leakage, instrumentation failure, or intraoperative mortality was observed. These findings are comparable to those reported from previous studies. Chen et al. ${ }^{11}$ reported a surgery-related complication rate of $17 \%$ (one postoperative hematoma, one neurologic deterioration, one CSF leakage, and one wound infection) following palliative surgery without anterior reconstruction and fusion. Similarly, another study ${ }^{24}$ reported a surgery-related complication rate of $6.8 \%$ (one CSF leakage and one local recurrence).

Improvement in patient quality-of-life is one of the primary goals of spinal metastasis palliative treatment. In the present study, we found that all HRQoL parameters, including pain VAS, ODI, and EQ5D5L utility-scale, significantly improved at a minimum of 3 months after surgery. There are few reports of outcomes of MESCC patients following palliative surgery. One prospective study of a cohort of 922 patients with spinal metastasis ${ }^{25}$ who underwent surgery found the EQ-5D, pain VAS, and Karnofsky Performance Scale (KPS) index all to be rapidly improved after surgery, and those results were sustained for up to 2 years after surgery among those patients who survived. That group concluded that surgical treatment in this patient population produces rapid pain relief, maintains ambulation, and improves patient quality of life. Similarly, another study ${ }^{23}$ that included pain control usage data and compared KPS scores between before and after surgery found that the median analgesic and steroid used to be significantly lower at 3 months and 6 months after surgery. Interestingly, multivariate analysis in that study revealed a better pre-operative KPS to be an independent predictor of survival in their study population.

\section{Limitations}

The primary limitation of this study is its retrospective design, which rendered it vulnerable to missing or incomplete data in some cases. Another notable limitation is that our limited study population was recruited from single centers. This could limit the generalizability of our findings to another care setting, and the small sample size may have impeded our ability to statistically reveal all existing differences and associations between the two surgical techniques. The last, the dropout rate in this study was high due to the relatively short survival duration of patients with MESCC. That acknowledged, the mean survival in our study was about 11.4 months, which is comparable to the mean survival duration reported by the previous studies, ${ }^{2,11,22-27}$.

\section{Conclusion}

Less invasive non-fusion without anterior reconstruction in MESCC patients yields a good result with a low complication rate, improvement in neurological function, and better HRQoL outcome scores. This surgical technique may be considered as a preferable choice of treatment in these groups of patients. However, A prospective multicenter study with a more extended follow-up period is warranted to confirm this study's findings and identify additional information that may enhance surgical approach-related decision-making in this patient population.

Received: 15 May 2020; Accepted: 17 August 2021

Published online: 01 September 2021

\section{References}

1. Patchell, R. A. et al. Direct decompressive surgical resection in the treatment of spinal cord compression caused by metastatic cancer: A randomised trial. Lancet (London, England) 366, 643-648. https://doi.org/10.1016/s0140-6736(05)66954-1 (2005).

2. Molina, C. et al. Posterior approaches for symptomatic metastatic spinal cord compression. Neurosurg. Focus 41, E11. https://doi. org/10.3171/2016.5.focus16129 (2016).

3. Harrington, K. D. The use of methylmethacrylate for vertebral-body replacement and anterior stabilization of pathological fracturedislocations of the spine due to metastatic malignant disease. J. Bone Joint Surg. Am. 63, 36-46 (1981).

4. Siegal, T., Tiqva, P. \& Siegal, T. Vertebral body resection for epidural compression by malignant tumors. Results of forty-seven consecutive operative procedures. J. Bone Joint Surg. Am. 67, 375-382 (1985).

5. Lewandrowski, K. U. et al. Anterior spinal arthrodesis with structural cortical allografts and instrumentation for spine tumor surgery. Spine 29, 1150-1158. https://doi.org/10.1097/00007632-200405150-00019 (2004).

6. Wang, J. C. et al. Single-stage posterolateral transpedicular approach for resection of epidural metastatic spine tumors involving the vertebral body with circumferential reconstruction: Results in 140 patients. Invited submission from the Joint Section Meeting on Disorders of the Spine and Peripheral Nerves, March 2004. J. Neurosurg. Spine 1, 287-298. https://doi.org/10.3171/spi.2004.1. 3.0287 (2004).

7. Ernstberger, T., Brüning, T. \& König, F. Vertebrectomy and anterior reconstruction for the treatment of spinal metastases. Acta Orthop. Belg. 71, 459-466 (2005).

8. Jandial, R., Kelly, B. \& Chen, M. Y. Posterior-only approach for lumbar vertebral column resection and expandable cage reconstruction for spinal metastases. J. Neurosurg. Spine 19, 27-33. https://doi.org/10.3171/2013.4.spine12344 (2013).

9. Gezercan, Y. et al. Single-stage posterolateral transpedicular approach with 360-degree stabilization and vertebrectomy in primary and metastatic tumors of the spine. World Neurosurg. 95, 214-221. https://doi.org/10.1016/j.wneu.2016.08.007 (2016).

10. Cahill, D. W. \& Kumar, R. Palliative subtotal vertebrectomy with anterior and posterior reconstruction via a single posterior approach. J. Neurosurg. 90, 42-47. https://doi.org/10.3171/spi.1999.90.1.0042 (1999).

11. Chen, Y. J., Hsu, H. C., Chen, K. H., Li, T. C. \& Lee, T. S. Transpedicular partial corpectomy without anterior vertebral reconstruction in thoracic spinal metastases. Spine 32, E623-626. https://doi.org/10.1097/BRS.0b013e3181573eea (2007).

12. Cobb, C. A. 3rd., Leavens, M. E. \& Eckles, N. Indications for nonoperative treatment of spinal cord compression due to breast cancer. J. Neurosurg. 47, 653-658. https://doi.org/10.3171/jns.1977.47.5.0653 (1977). 
13. Walsh, G. L. et al. Anterior approaches to the thoracic spine in patients with cancer: Indications and results. Ann. Thorac. Surg. 64, 1611-1618. https://doi.org/10.1016/s0003-4975(97)01034-5 (1997).

14. Barron, K. D., Hirano, A., Araki, S. \& Terry, R. D. Experiences with metastatic neoplasms involving the spinal cord. Neurology 9 , 91-106. https://doi.org/10.1212/wnl.9.2.91 (1959).

15. Bach, F. et al. Metastatic spinal cord compression. Occurrence, symptoms, clinical presentations and prognosis in 398 patients with spinal cord compression. Acta Neurochir. 107, 37-43. https://doi.org/10.1007/bf01402610 (1990).

16. Barzilai, O., Fisher, C. G. \& Bilsky, M. H. State of the art treatment of spinal metastatic disease. Neurosurgery 82, 757-769. https:// doi.org/10.1093/neuros/nyx567 (2018).

17. Matsumura, A., Hoshi, M., Takami, M., Tashiro, T. \& Nakamura, H. Radiation therapy without surgery for spinal metastases: Clinical outcome and prognostic factors analysis for pain control. Glob. Spine J. 2, 137-142. https://doi.org/10.1055/s-0032-13269 48 (2012).

18. Lee, S. H. et al. Can the spinal instability neoplastic score prior to spinal radiosurgery predict compression fractures following stereotactic spinal radiosurgery for metastatic spinal tumor? A post hoc analysis of prospective phase II single-institution trials. J. Neurooncol. 126, 509-517. https://doi.org/10.1007/s11060-015-1990-z (2016).

19. Laufer, I. et al. The NOMS framework: Approach to the treatment of spinal metastatic tumors. Oncologist 18, 744-751. https://doi. org/10.1634/theoncologist.2012-0293 (2013).

20. Altaf, F. et al. Evidence-based review and survey of expert opinion of reconstruction of metastatic spine tumors. Spine $\mathbf{4 1}$ (Suppl 20), S254-s261. https://doi.org/10.1097/brs.0000000000001819 (2016).

21. Wilson, J. R., Hashimoto, R. E., Dettori, J. R. \& Fehlings, M. G. Spinal cord injury and quality of life: A systematic review of outcome measures. Evidence Based Spine Care J. 2, 37-44. https://doi.org/10.1055/s-0030-1267085 (2011).

22. Itshayek, E. et al. Ambulation and survival following surgery in elderly patients with metastatic epidural spinal cord compression. Spine J. 18, 1211-1221. https://doi.org/10.1016/j.spinee.2017.11.020 (2018).

23. Ju, D. G. et al. Factors associated with improved outcomes following decompressive surgery for prostate cancer metastatic to the spine. Neurosurgery 73, 657-666; discussion 666. https://doi.org/10.1227/neu.0000000000000070 (2013).

24. Chang, C. C. et al. Palliative transpedicular partial corpectomy without anterior vertebral reconstruction in lower thoracic and thoracolumbar junction spinal metastases. J. Orthop. Surg. Res. 10, 113. https://doi.org/10.1186/s13018-015-0255-z (2015).

25. Choi, D. et al. Rapid improvements in pain and quality of life are sustained after surgery for spinal metastases in a large prospective cohort. Br. J. Neurosurg. 30, 337-344. https://doi.org/10.3109/02688697.2015.1133802 (2016).

26. Mühlbauer, M., Pfisterer, W., Eyb, R. \& Knosp, E. Noncontiguous spinal metastases, and plasmocytomas should be operated on through a single posterior midline approach, and circumferential decompression should be performed with individualized reconstruction. Acta Neurochir. 142, 1219-1230. https://doi.org/10.1007/s007010070018 (2000).

27. Kondo, T., Hozumi, T., Goto, T., Seichi, A. \& Nakamura, K. Intraoperative radiotherapy combined with posterior decompression and stabilization for non-ambulant paralytic patients due to spinal metastasis. Spine 33, 1898-1904. https://doi.org/10.1097/BRS. 0b013e31817c0410 (2008).

\section{Acknowledgements}

The authors gratefully acknowledge Miss Nhathita Panatreswas for her assistance with statistical analysis, editing manuscript and journal submission process.

\section{Author contributions}

W.S, R.M. and L.P. prepared proposal and provided raw data. S.S. collected data and wrote and edited the main manuscript text. S.B. edited the main manuscript text. All authors reviewed the manuscript.

\section{Funding}

This was an unfunded study.

\section{Competing interests}

The authors declare no competing interests.

\section{Additional information}

Correspondence and requests for materials should be addressed to P.L.

Reprints and permissions information is available at www.nature.com/reprints.

Publisher's note Springer Nature remains neutral with regard to jurisdictional claims in published maps and institutional affiliations.

(c) (i) Open Access This article is licensed under a Creative Commons Attribution 4.0 International License, which permits use, sharing, adaptation, distribution and reproduction in any medium or format, as long as you give appropriate credit to the original author(s) and the source, provide a link to the Creative Commons licence, and indicate if changes were made. The images or other third party material in this article are included in the article's Creative Commons licence, unless indicated otherwise in a credit line to the material. If material is not included in the article's Creative Commons licence and your intended use is not permitted by statutory regulation or exceeds the permitted use, you will need to obtain permission directly from the copyright holder. To view a copy of this licence, visit http://creativecommons.org/licenses/by/4.0/.

(c) The Author(s) 2021 